\title{
A Study on Service Marketing of University Libraries in the New Media Environment
}

\author{
Yi Zheng, Lan Du \\ Jinan University Library, Guangzhou, China \\ Email:101199552@qq.com
}

How to cite this paper: Zheng, Y. and $\mathrm{Du}$, L. (2018) A Study on Service Marketing of University Libraries in the New Media Environment. Open Journal of Social Sciences, 6, 223-233.

https://doi.org/10.4236/jss.2018.611016

Received: October 29, 2018

Accepted: November 20, 2018

Published: November 23, 2018

Copyright $\odot 2018$ by authors and Scientific Research Publishing Inc. This work is licensed under the Creative Commons Attribution International License (CC BY 4.0).

http://creativecommons.org/licenses/by/4.0/

\begin{abstract}
As the technical support and communication platform, new media plays a critical role in the construction and service of digital libraries. Furthermore, it has become an imperative form for libraries to carry out service marketing and promotion, demonstrating the expansion of services in libraries. The article expounds the inevitability of university library service marketing under the new media environment, proposes marketing strategy, and finally enumerates the specific application of various new media technologies in the service marketing of university libraries.
\end{abstract}

\section{Keywords}

New Media, University Library, Service Marketing

\section{Introduction}

New Media is a form of media emerging from the new technology support system. It features great variety, strong interactivity, broad channels, high coverage, accuracy, high cost efficiency, and ease to promote. New media covers all forms of digital media including all digital traditional media, network media, mobile media, digital television, digital newspapers and magazines, etc. In comparison with newspapers, outdoor messages, broadcasting and television as four forms of traditional media, new media has been vividly described as the "fifth media".

With wide application of information and network technology, various for-profit or non-profit information service organizations have been rapidly developing. The traditional university library service marketing and promotion is also facing unprecedented challenges, and its marketing strategy is gradually diversified. Driven by the new media environment that has revolutionized Web 2.0, the marketing of library services is constantly evolving and improving. Due to the 
enhanced accessibility of information, the behaviour of readers to obtain information has changed in the new media environment. In particular, the traditional means of service marketing and promotion no longer attract readers' attention. Hence, new media, as the technical support and communication platform, is of paramount importance in the construction and service of digital libraries and represents the expansion of library services. The new media environment differs in the following aspects.

\subsection{The Spread of Service Marketing in the New Media Environment}

The main advertising channels of university libraries include: 1) posters, rollup displays and other promotional materials; 2) literature research courses and special seminars and 3) publishing news bulletins and resources on the library homepage [1]. However, these channels have certain limitations as they may only reach those who frequently visit the library or browse the library homepage. Therefore, it lacks the possibility to identify potential readers. Even in public bulletin boards with large traffic outside the library, such as canteens, dormitories, and teaching buildings, it is easy to be covered by other advertising materials, which may be easily ignored by teachers and students.

On the other hand, new Medias, represented by the internet, mobile phones and PCs, is widely welcomed and utilised by students. As a result, library services and resources may be better spread on the university campus with the help of new media tools. According to the "Fifteenth National Reading Survey Report" issued by the China Press and Publication Research Institute in 2018, the contact rate of digital reading (network online reading, mobile phone reading, e-reader reading, Pad reading, etc.) is $73.0 \%$. In $2016,68.2 \%$ increased by 4.8 percentage points. The contact rate of digital reading was $64.0 \%$, an increase of 5.9 percentage points year-on-year, which was significantly higher than paper reading for the first time. The development of digital reading has improved the national comprehensive reading rate and the digital reading mode contact rate, and the overall reading population has continued to increase, but it has also brought about a new trend of slowing the growth of book reading rate. In digital reading, WeChat reading is the most popular. According to statistics, $63.4 \%$ of adult nationals have read WeChat in 2017, an increase of $1.0 \%$ compared to $62.4 \%$ in 2016. By combining the traditional means of advertisement and new media technology, the service marketing prevails to be more effective and covers a broader range of the audience.

\subsection{The Interactivity of Service Marketing in the New Media Environment}

The library services and resources are introduced to readers in a unidirectional manner under the traditional service marketing model, which has a lack of interactivity with readers. Service marketing in the new media environment, however, interacts with readers through internet and mobile phone. The use of such 
new media tools enables the libraries to understand the readers' need for information and their customer experience. Moreover, libraries may adjust the marketing strategy based on readers' feedbacks and opinions in order to better promote their services and resources and enhance the library's influence. Teachers and students can subscribe to personalised library services based on their needs for information and interest. In response to improved accuracy of service push, such customisation of library services has gained popularity amongst readers.

The strong interactivity of service marketing and promotion in libraries under the new media environment has shifted the one-way communication mode of traditional service marketing to interactive marketing.

\subsection{The Cost Efficiency of Service Marketing in the New Media Environment}

Whilst there is the payment to media is embedded in the traditional marketing model, new media marketing incurs a lower cost due to the network platform. Many free online platforms can gather popularity in a short period of time, form a diffusion spread, and improve marketing effects [2]. The library uses the online platform under the new media environment such as blog, Weibo, and Wikipedia to conduct service marketing and promotion, which can massively reduce the marketing cost because of the interactive characteristic of the new media could stimulate students' attention and participation in the event, cut down paper waste and mitigate environmental pollution. Reader participation has become more convenient and faster, thus improving the service efficiency of the library, and positively impacting the university students' information literacy.

\section{Service Marketing Strategy of University Libraries in the New Media Environment}

In 1990, American scholar Robert F. Lauterborn proposed the 4C marketing mix model in his "New Marketing Litany: Four P's Passe: C-Words Take Over" article: customer, cost, convenience and communication [3]. As this marketing theory emphasises on the consumer demand, which is consistent with the readercentric service philosophy in developing literature resources to ensure reader satisfaction [4]. Hence, the authors consider that is it suitable to introduce the $4 \mathrm{C}$ 's model into the service marketing of university library in the new media environment.

\subsection{Establish a Reader-Centric Marketing Strategy}

In the new media environment, university students are increasingly relying on new media for a variety of tasks such as course selection, homework, dating and entertainment. With the continuous development of digital technology and network technology, the role of university libraries has shifted from a simple book storage facility to a university's information and culture communication centre. Therefore, the passive service with the library website can no longer suf- 
fice the needs of users. It is required to embed library service into the working and learning environment of readers so that the readers can access the online library services without having to leave their familiar environment (i.e. new media environment) [5].

\subsubsection{Push Service Based on Reader Type}

Different readers have different information needs. Personalised push services using RSS, mobile library and other technologies based on the target audience's information needs have gained much popularity, especially amongst those who are working on their graduation thesis or searching for job opportunities. Furthermore, the service can be extended to manage the graduation process and interact with alumni through Weibo and WeChat. At the start of new semesters, libraries may target freshmen through various forms of new media tools to make optimal use of the library services. For sophomores and juniors, regular push service may be provided to share literature relevant to their majors (e.g. psychology, exams and social practice).

\subsubsection{Focus on the Promotion of Personalised Services}

The library personalisation service enables readers to obtain services and resources of their interest in a timely manner. In addition, the library can also understand the reading preferences according to the subscription content of the readers and provide a basis for better service in the future.

\subsection{Cost Saving Strategy}

Many university libraries have created "service promotion month" to promote the library resources and services as well as increase brand awareness. In addition to preparing various prizes to increase the publicity of the event, the library also needs to pay for promotional materials such as roll-ups, posters, banners, etc., which result in increased expenditure, yet the results are often unsatisfactory. Conversely, the interactive characteristic of the new media stimulates students' attention and participation in the event at a reduced cost.

\subsubsection{The Benefit of Free New Media Tools}

The use of online platforms in promoting library services and resources can make up for the lack of funds. Currently, most of the blogs, Weibo, social networks, and Instant Messaging applications are free in China. The library can apply for certification of official identity on various network platforms. Special personnel will be in charge of the release, reply and management of network information. Furthermore, the administrator will also oversee advertising of service, resources and announcements to increase the attractiveness for both internal and external followers.

\subsubsection{Introducing Game Marketing}

On January 8, 2011, the New Media Alliance published the "2011 Horizon Report", stating that game-based learning may become the mainstream application 
technology in the next two to three years [6]. Game-based marketing was introduced to university library marketing, revolutionising the original concept of "knowledge-based". It has been argued that using game as a way to increase reader participation and trigger readers' interest is far more valuable than distributing high-value prizes. For example, the mini game developed by Tsinghua University Library "Arranging the shelf", as part of the promotion series "Fall in Love with the Library", has helped readers to get familiarised with the library collection distribution and reference management system with the purpose of improving their literature search efficiency. The game won $10^{\text {th }}$ IFLA International Marketing Awards in 2012 [7].

\subsection{Marketing Strategies to Improve Readers' Convenience}

Library service marketing in the new media environment should maximize the convenience of readers, allowing readers to use the mobile phone, tablet, e-book reader and other tools to access library services and resources anytime and anywhere when connected to the Internet.

\subsubsection{Providing Instant Services}

First of all, in order to ensure that readers can keep up with library news announcements, the latest resources, activities and other information, librarians should promptly publish promotional notices in all new media platforms and follow up. Secondly, the front office positions at the library should be equipped with QQ and other types of instant messaging application for the convenience of remotely answering to the readers' inquiries. In this way, readers do not have to leave their home to experience the library service.

\subsubsection{Emphasis on Promoting Reading through New Media}

University libraries can promote e-book reading to teachers and students in new media platforms to emphasise on the fun of reading. By shifting the utilitarian tendency to promote reading to creating a relaxed and pleasant reading space, it encourages the students to rediscover the fun in reading and attract students read in an active manner as they are not obliged to do so. Additionally, it should be noted that introducing "must-read books" without due consideration given to the readers preference may cause the psychological resistance from students and should be avoided [8]. Finally, the goal of promoting reading through new media is to making reading mainstream.

\subsection{Marketing Strategies to Strengthen Communication with Readers}

On the one hand, the strong interactivity of new media is beneficial to the library to strengthen communication with readers. Its service marketing method includes creating library homepage, blog, Weibo, WeChat, BBS, RSS, and SNS as interactive communication platform for users. The interactive communication platform provides the timeliest communication with users through personalised 
call centre services. The virtual experience marketing platform allows readers to better understand the services of the library and improve service efficiency.

On the other hand, information communication and feedback are essential in the marketing of library information services. Its purpose is to gradually improve the marketing strategy of the library based on information communication and feedback [9]. Therefore, using new media to gathering readers' opinions and mastering the reader's information needs enable libraries provide better information services for teachers and students of the school.

\section{The Application of New Media Technology in University Library Service Marketing}

At present, the ways in which university libraries use new media to conduct services and marketing mainly include: mobile phone services, network marketing under the Web2.0 environment (simple aggregation RSS, blog, microblog, instant messaging, social network SNS and WeChat).

\subsection{Mobile Phone Library/Mobile Library}

Mobile phone media realises the dissemination and personalisation service of text, audio, video and other media content through mobile terminal carrier and wireless network. It has better mobility, portability, real-time and interaction than other media and thus is widely accepted by the public, especially by college students [1]. The use of mobile media has become one of the ways in which many university library resources and services are marketed and promoted. Through the mobile phone library or mobile library, you can push all kinds of notifications to readers, such as opening and closing time, expiration of books, book pick-up appointments, new book notifications, OPAC inquiry service and online reading of a wide assortment of literature ${ }^{1}$ through mobile devices. For example, users can save interesting literature and subscribe library services based on their needs in the library of Jinan University. The users are also free to choose between wap and colourful version using digital resources of the library [10].

With the maturity of $4 \mathrm{G}$ technologies, the continuous improvement of operating mechanisms and the popularity of smart phones, more and more university libraries will use mobile media to promote library resources and services, so that readers feel that omnipresence of library resources.

\subsection{Network Marketing under the Web2.0 Environment}

Online marketing is a new marketing method that emerges with the widespread use of the Internet. In essence, it aims to maximise customer satisfaction, in order to increase market share and profitability. In comparison with other traditional marketing methods, online marketing has the characteristics of wide coverage, real-time, interactive participation, enhanced communication, low cost, and scalability [11]. There are several aspects in the way that libraries use new

${ }^{1}$ E-books, journals, newspaper, scholar thesis and videos. 
media to promote online marketing.

\subsubsection{RSS Marketing}

Libraries apply RSS (Really Simple Syndication) technology for online marketing, mainly through RSS feeds to push library services and resources, thereby improving the utilisation rate of library resources and information services. RSS push service has the characteristics of fast update frequency, time efficient, and service customisation. It is one of the most effective ways for libraries to promote personalised services.

The contents of RSS services promoted by domestic and foreign university libraries mainly include: 1) news, including various event notifications, latest lectures, new electronic resource, latest announcements, training notifications and exhibition activities [12];2) new book notification; 3) subscription services of journals and databases; 4) subscription services of forums and multimedia resources; 5) research tracking and special topic services; 6) reference services 7) online resource navigation services, etc.

\subsubsection{Blog Marketing}

Blog marketing is online marketing through blogging websites or blog forums. It has flexible and diverse forms of expression. The volume of information may vary and can be easily indexed and searched by search engines. Furthermore, it also has the characteristics of low cost, high credibility, high speed of information distribution and autonomous communication.

As an effective way for libraries to realise personalised service, blog has become a hub for instant communication between libraries and users and serves as an important information platform [13]. The target audiences of university library blogs are mainly teachers and students in the school. It provides various news announcements, event information and resources (i.e. professional databases, reference websites, web search tools, and open source software and multimedia technology) for the teachers and students. It is a real-time dynamic information service, which has become an effective marketing method for sharing library resources and improving the utilisation rate of information.

\subsubsection{Weibo Marketing}

Weibo (micro blogging) is an integrated and open online social service emerging from the Web2.0 era. It is a platform for information sharing, dissemination and acquisition based on user relationships. With its speed, precision, ease-to-operate, and instant interaction, Weibo is gaining ground against blogs, BBS and IM and has become a vital online communication tool [14].

In August 2009, Sina Weibo quickly became popular in China and even overseas. It is ranked first amongst other Weibos provided by Tencent, Sohu, NetEase (163.com) in China. Through a verified official Weibo account, libraries introduce library services to readers, and further expand the library's reach by launching topics and interacting with readers. It also explores potential target markets. 119 Weibo accounts of verified official university library accounts have 
been identified through a keyword search for "library". The top ten universities that are more active are listed in Table 1. It can be seen from the table that there are more than 10,000 followers in these college libraries, which are highly regarded by the teachers and students of the school and university library community.

\subsubsection{Instant Messaging Marketing}

IM (Instant Messaging) marketing is a marketing tool for product and brand promotion through instant messaging tools. The library uses free IM tools to provide readers with real-time consulting services, which can efficiently and promptly interact with readers, push resources and services, and tap into potential target markets [15]. It has been suggested that the development of IM service marketing is more advanced in US universities. According to the research data of Library Success: A Best Practices Wiki [16], as of September 2, 2018, there are 799 college libraries in the United States that use IM tools for consulting services. The IM tools used are MSN, Jabber, GTalk, ICQ, Yahoo, etc. Domestic university libraries (e.g. Peking University Library and Jinan University Library) usually use IM tools like QQ and MSN to interact with readers.

\subsubsection{Social Media Marketing}

Social network sites (SNS) is a social network that integrates functions such as blogs, emails, instant messaging, bulletin boards, and personal spaces. By integrating services into social media, libraries may expand the size of their target audience, understand the needs of readers in real time, enhance influence of libraries in reader's personal life [17], and strengthen the service brand.

Since 2006, many US college libraries have set up their communication platforms on social media platforms such as Facebook, Myspace, and Youtube. A total of 159 university libraries have used the Chinese social media platform

Table 1. Ranking of official university library Weibo account activities ${ }^{2}$.

\begin{tabular}{|c|c|c|c|c|c|c|c|}
\hline Ranking & $\begin{array}{c}\text { Name of } \\
\text { Weibo account }\end{array}$ & $\begin{array}{l}\text { Number of } \\
\text { tweets }\end{array}$ & $\begin{array}{c}\text { Number } \\
\text { of followers }\end{array}$ & Ranking & $\begin{array}{c}\text { Name of } \\
\text { Weibo account }\end{array}$ & $\begin{array}{l}\text { Number } \\
\text { of tweets }\end{array}$ & $\begin{array}{c}\text { Number of } \\
\text { followers }\end{array}$ \\
\hline 1 & $\begin{array}{c}\text { Tsinghua } \\
\text { University Library }\end{array}$ & 6642 & 52283 & 2 & Wuhan University Library & 5247 & 34,900 \\
\hline 3 & $\begin{array}{c}\text { Peking } \\
\text { University Library }\end{array}$ & 3093 & 33309 & 4 & Xiamen University Library & 2852 & 28,693 \\
\hline 5 & $\begin{array}{l}\text { Fudan } \\
\text { University Library }\end{array}$ & 2105 & 24663 & 6 & Sichuan University Library & 9175 & 24,138 \\
\hline 7 & $\begin{array}{c}\text { Guangdong } \\
\text { University of Foreign } \\
\text { Studies Library }\end{array}$ & 2330 & 19995 & 8 & Tongji University Library & 12,154 & 18,284 \\
\hline 9 & $\begin{array}{c}\text { Chongqing } \\
\text { University Library }\end{array}$ & 3633 & 18735 & 10 & Jinan University Library & 4297 & 15,218 \\
\hline
\end{tabular}

${ }^{2}$ The data was collected on the October 1, 2018 and ranked in descending order of the number of Sina Weibo followers. 
"Renren.com" until September 2, 2018 to provide services and have received much attention [18]. Tsinghua University has the most attention with 7000 followers for their University Library Book Club.

\subsubsection{WeChat Marketing}

WeChat is a voice product of Tencent. The current popular mobile communication software supports sending voice messages, videos, pictures and texts through group chats [19]. WeChat marketing is online marketing methods that have gained much popularity with the rise of WeChat. After the library opens the WeChat public account, the reader adds it as a "friend", and then library can use the WeChat platform to promote services and resources to the subscribers, forming a peer-to-peer marketing method. The WeChat public platform was officially launched on August 23, 2012, and was positioned as an online promotion platform for celebrities, government officials, media, enterprises and other institutions. However, WeChat public platforms have been gradually mainstreamed into an online marketing method. WeChat as an online marketing tool not only provides libraries a mean to promote library services and resources, but also enables instant communication and problem-solving readers. With the use of texts, pictures and voice messages, the communication and interaction with audiences is said to be comprehensive and multidimensional.

For example, The WeChat of Jinan University Library launches four times per month of daily graphic messages, and the menu bar provides bibliographic inquiry, borrowing information, seat reservation, latest information, resource dynamics, welcome new micro-station, etc. Users can also use WeChat dialog box to conduct an online consultation. The WeChat of the East China Normal University Library supported the "card package" service, allowing WeChat to replace the library card function. We can also use WeChat scan code instead of swiping cards to enter and borrow books without a library card. The WeChat of Guangzhou Library menu bar provides a "two-dimensional code electronic certificate" instead of an entity certificate. More and more university libraries use WeChat service platform to provide various business services, carry out library marketing and reading promotion, and build a new mode of better communication with readers [20].

\section{Conclusion}

The user-centric new media has developed rapidly, providing a good promotion platform for university library service marketing. Nevertheless, the marketing and promotion conducted by Chinese university libraries using new media is still at its infancy. Nevertheless, the use of new media technology plays a critical role in the service marketing of university libraries in terms of expanding its reach to audiences, which carries both practical and theoretical implications. Therefore, it is imperative for university libraries to optimise their marketing model, in particular take advantage of new media in the coming years. 


\section{Project}

Guangdong Provincial Library Association Project (GDTK1809): Research on the annual reading report of academic libraries based on personas.

\section{Conflicts of Interest}

The authors declare no conflicts of interest regarding the publication of this paper.

\section{References}

[1] Sun, X.L. and Ning, Z.B. (2012) Reflections on Library Service and Publicity in the New Media Environment. Library Theory and Practice, 14-16.

[2] Zhou, K. (2012) Research on New Media Marketing Channels and Strategies of Traditional Books. Publishing Science, 13-17.

[3] Kotler, P. (2006) Marketing Management. 12th Edition. Shanghai People's Publishing House, Shanghai.

[4] Zhang, J.B. (2007) Research on Marketing Strategy of Digital Library. Information and Documentation Work, 76-78.

[5] Hu, X.J. (2008) Embedding Library Services into User Environment on Browser Toolbar. Shanghai University Library and Information Service Research, 8-11.

[6] Johnson, L., et al. (2011) 2011 Horizon Report: New Technologies in the Field of Education and Learning. Library and Information Work, 15-18.

[7] Tsinghua Library "Loves Library Video and Arrangement Games" Won the 10th IFLA International Marketing Award.

http://www.tsinghua.edu.cn/publish/news/4205/2012/20120327133548364769738/2 0120327133548364769738_html

[8] Yuan, S.F. (2013) Research on New Media Reading Promotion Strategy in University Libraries. Modern Information, 74-77, 81.

[9] Zhu, X.Z., Chen, X.T. and Zhang, Y.G. (2007) Marketing Strategy of University Libraries under the Network Environment. Modern Information, 24-26, 29.

[10] Jinan University Mobile Library. http://lib.jnu.edu.cn/service/ServInfoOneSub.action?id=67\&subjectid=22\&expanda $\underline{b l e}=22$

[11] Fang, H., Ge, H.L. and Fang, S.H. (2010) Research on the Application of RSS in Library Online Marketing. Library Research and Work, 19-23.

[12] Shen, Y.S. (2012) Investigation on the Status Quo of RSS Application in American University Libraries and Its Enlightenment. Library Forum, 61-64.

[13] Tian, J., Zhang, C.W., Han, R.P. and Ma, J. (2009) The Development of Foreign Library Information Services from Foreign Library Blogs. Library Construction, 44-47.

[14] Huang, S.M. (2012) Research on the Characteristics and Development Strategies of Library Weibo. Journal of Academic Libraries, 78-83.

[15] Du, L. (2016) Research on Micro-Marketing Practice of University Libraries in the New Media Environment-Case Studies of University Libraries in Guangzhou. University Library Work, 9-13.

[16] Libraries Using IM Reference. http://www.libsuccess.org/Libraries_Using_IM_Reference 
[17] Peng, Y.F. (2012) Comparative Study on the Application of Social Network in University Libraries at Home and Abroad. Library Science Research, 79-81.

[18] Renren.com. http://www.renren.com

[19] Baidu Encyclopedia: WeChat Marketing. http://baike.baidu.com/link?url=muZl9zXwIvw4ZGk0KZ_ls1VawAinVEkbLuzskLx LS-iKfVPURb0VYtWc5CFMC7LJNvWhFWJHvTX0Wx8aZwaz5a

[20] Du, L. and Wang, Z.Q. (2017) The Empirical Research on Users Information Behavior of the WeChat Public Platform in University Library-_An Empirical Study of Jinan University Library. Research on Library Science, 84-90. 